\title{
Thoughts on Double Alleviation Policy: A Background-based International Comparison of Shadow-education Policies
}

\author{
Sini $\mathrm{Wu}$ \\ Manchester Institution of Education, University of Manchester \\ *Corresponding author. Email: sini.wu@postgrad.manchester.ac.uk
}

\begin{abstract}
The Chinese State Council announced Shuangjian Policy (aka. Double Alleviation Policy) intending to alleviate students' pressure. The purpose of this conceptual article is to predict the possible consequences on Chinese tutoring institutions by conducting a comparative study of various educational policies confronting shadow education among Korea, the United States, and China. The theoretical framework adopts the policy-making circle (i.e. decision, implementation, and evaluation). The findings showed that China and Korea had placed strict restrictions on private tutoring, while the US administrator has joined supplemental tutoring's efforts in the sphere of public education through collaboration with private sectors. Schooling concerns, private education's socioeconomic repercussions, the state of the market economy, and traditional governmental accustoms in diverse contexts are all shown to have a substantial impact on educational policies concerning shadow education in different countries.
\end{abstract}

Keywords: Double Alleviation Policy, Shadow Education, China, Korea, America.

\section{INTRODUCTION}

In late July of 2021 Chinese State Council launched Shuangjian Policy (aka. Double Alleviation Policy) to reduce the dual burden that Chinese students face from both schools and after-school tutoring programs. This policy focused on four aspects: reducing school homework, improving the quality of school education, and regulating supplemental private tutoring [1]. As the official profile pointed out, this newly issued policy will strengthen schools' dominant status in K12 education, promote off-campus tutoring governance, and relieve parents' educational anxiety.

The newly released policy sparked the discussion about shadow education. Researchers have both considered its pros and cons with many regards [2-3]. Some researchers regard this as being beneficial for its expanding versatility and prompting human capital for the worldwide population [4]. On the other hand, parents' concerns about children's employment-seeking and the expectations of their success accelerate the emergence of shadow education [4]. Bray [5] considered that it is likely to continue to expand and become diverse worldwide. However, other researchers pointed out the flaws of the development of shadow education, including problematic issues of social inequities, early pressure for childhood, and possible disruption and waste of sources for more potential productive uses [2].

As Yang pointed out, there is no need for the government to take measures when little or no adverse effect is shown for the private education industry. However, suppose the shadow industry, especially class-based private tutoring, reached such a relatively large scale that could affect the schooling system and social equity. In that case, the administrator should be alarmed for better control. Unfortunately, the enormous scale of the shadow education industry in China has grown to be an unignorable fact for the Chinese administration to take measures.

Many studies have explored shadow education [3][6]. In particular, some researches tend to have an international perspective and draw a worldwide map of governments' policies towards shadow education. However, most international evidence about shadow-education policies in the previous studies lacks discussions of the policies' corresponding diverse backgrounds. Therefore, to have a deep understanding of an educational policy, we should analyze it based on 
understanding the corresponding national backgrounds behind the policy.

This paper makes efforts in integrating an image of previous literature about cross-culture shadow education, endogenous backgrounds and national administrations' corresponding policies, with a purpose to sketch a global picture by identifying different nations' patterns of shadow-education policies and their respective corresponding backgrounds, which were considered to be the potential motives influencing administrators' decisions.

\section{SHADOW EDUCATION}

\subsection{The definition}

According to Bray [5], the conception of shadow education dates back to the early 1990s. A Singapore institute initiated an investigation of a kind of out-of-school private tutoring. After the original research, more researches have been devoted to this field. Marimuthu et al. was the first expert to commence the prevalent "practice of private education" as a "shadow educational system", and noted that private tutoring programs happened at the elementary and secondary stages. This metaphor later became popularized in slightly distinct versions. Then shadow education was defined by Steven and Baker as "a set of educational activities that occur outside formal schooling and designed to enhance the student's formal school career" which later occurred to be the settled term of private tutoring programs corresponding to school course study [7]. Bray mentioned the feature of privateness for shadow education: tutoring is supplied to get a charge, and unpaid private tutoring offered by teachers, families or volunteers should not be considered part of it [6]. Therefore, from the past literature, this essay considers shadow education has the following features:

- Academic subjects supplement students' study of specific courses in schooling, such as mathematics, chemistry, etc. Therefore, artistic or physical skills which aren't examined subjects are precluded from the list.

- Privately, tutoring is provided in additional occasions out of schooling time, such as in private institutions, designated private locations, or schools.

- Fee-paying work, supplementary tutoring is offered for profits.

\subsection{Intensity and scale}

Shadow education has existed and expanded worldwide in different cultures in the past decades [6]. Eilor added that the intensity of private tutoring diverged in various regions, and this industry continued to increase tremendously and become extensively conspicuous across all sub-sectors. Silova also remarked private tutoring programs became "a vast enterprise" after the early 1990s. The shadow-education scale used to be modest, with her research data from 12 Eastern European and Asian countries linked to the Soviet Union. Ireson and Gordon et al. mentioned that shadow private tutoring might be less evident in other societies. Still, its scale has increased to be more noticeable with various dynamics in western Europe and North America [8][9]. Tutoring has been increasingly reported in low-income countries [3]. For example, in Kenya, it was found by Nzomo et al. that around $68.6 \%$ pupils receive tutoring from a domestic sample of 3233 Standard six pupils. In Vietnam, shadow education cost $20 \%$ of family expenditures with a high inclination from urban areas. Byun et al. draw data from the 2012 PISA survey within 65 countries, which has assessed 15-year-old students for their academic performance since 2000. They found the cross-culture prevalence of students' attending shadow education. The average portion for 15 -year-old students who took private tutoring in the national student population is approximately $33 \%$ among 64 worldwide countries, in which 7 nation samples are chosen to be listed below in Figure 1.

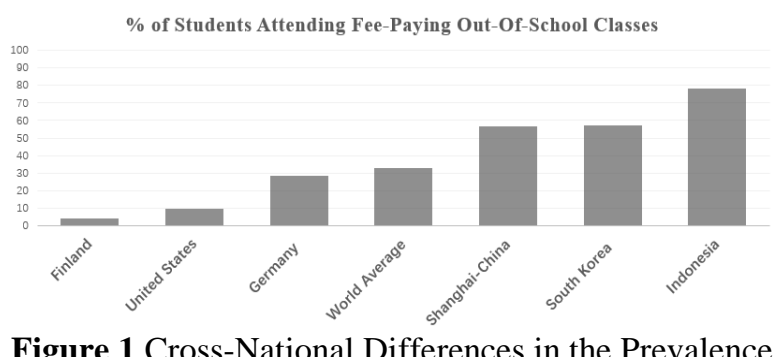

Figure 1 Cross-National Differences in the Prevalence of Attending Fee-paying Out-of-school Classes

\subsection{Participator}

SE often involves commercial institutions, college students, secondary school students, professional educational workers, in-service school teachers, etc. Companies have systematically offered private tutoring for some decades. For example, Kumon, a reputable multinational firm that originated in 1954 in Japan, claimed to offer private tutoring for over 4 million students from 45 countries for math and languages [10]. On other occasions, some mainstream teachers also offer private supplementary education to their own pupils. The reasons are probably low salaries they earn from their in-service schools can't support their basic needs. According to Yang, shadow education in Eastern Europe greatly increased after the early 1990s due to economic bankruptcy, which forced teachers to struggle for extra interests to compensate their living fees. Nevertheless, Bray commented on this pattern of education that mainstream teachers may omit part of the curriculum left to their private tutoring session as signs of extortion, which induce more pupils to their after-school business 
[6]. Besides, some tutors of secondary school pupils are students from the tertiary system: college students. They offer such a service to gain extra earnings for their college living. Students in high school cater even some elementary students. According to Bray, though these groups of people usually don't hold professional tutoring certificates as qualification, they have a good connection with students due to their adjoining ages [6]. Moreover, some retired teachers are willing to participate in this private program for additional income and continuous contribution, lacking proficiency in cyber techniques and communication devices [6].

Students from primary and secondary levels are the receivers of shadow education due to various motives. Family factors can drive students to attend shadow education. According to Kim, in Korea, due to "the decreasing number of children in a family, and good college credentials persistent important", new-generation families gave "more individual caring for their children's academic achievement that previous parents", which is similar to current China. Glasman pointed out that parents can consider private tutoring to gain peace and reduce tension within their family while children are well catered to in private tutoring centers. It is also reported by Byun et al. that students from higher socioeconomic family backgrounds are more likely to utilize private tutorial services compared with students from poorer family backgrounds.

\section{EDUCATIONAL POLICIES}

Roberts et al. considered policymaking in the education sector to be complicated where unexpected consequences generally arise. They proposed six stages as a cycle for an educational reform, in which the following sectors are introduced: (1) problem definition, (2) diagnosis of the causes of educational problems, (3) policy development, (4) policy decision, (5) policy implementation, (6) evaluations [24]. According to Roberts et al., in the first stage of definition, the educational problems need to be perceived and defined both descriptively and normatively. In the second stage of diagnosis, the educational reformer needs to work backwards to understand what lies inherently behind the unsatisfactory needs disappointing results. In the third stage of policy development, policymakers decide what to be done. In the fourth stage of a policy decision, principles search to decide after political analysis. In the fifth stage of implementation, the administrator should conduct its designed plan. In the sixth evaluation stage, the actual effects of the new educational innovations or policies should be determined. Warwick et al. demonstrated a transaction model to analyze the implementation of social programs [11]. It proposed twelve issues as indicators determining the employment of a policy or innovations, which include "organizational intelligence, process, technologies, management and organization, culture, politics, field implementers, clients, facilities, costs, quantity and quality of services, and institutionalization of change." (p.i). Williams and Cummings generalizes the basic features of educational reforms, including the persistence of past ideology to exert impacts on the new and reproducing indigenous paradigms instead of global favored patterns [12]. He argued that the existing core institutional patterns significantly impact educational systems, and the reformer should consider that factor. The trajectory of reform can possibly be shaped or agitated by diverse mutations, particular contexts, and intricate power dynamics throughout the whole course [12].

This article takes advantage of the framework of policy making by Roberts et. al. Furthermore, it innovates the previous stages into three new aggregated ones: Stage 1: policy decision, Stage 2: implementation, Stage 3: evaluation. The three stages of a cycle for policy-making are used to analyze three prototypes of countries with distinguished patterns of shadow-education policies in the following discussion.

\section{DISCUSSION}

\subsection{Comparative study of educational policies in Korea, America and China}

\subsubsection{Korea}

\subsubsection{Policy decision}

Korea is reputable for its large-scale shadow education with its lengthy tutoring history, and various governmental actions were taken to address these problems with hampered achievements [6]. Seth considered the Korean educational system, which emphasized shadow education as a compelling factor contributing to national economic success [13]. He pointed out its focus on "teacher authority and intense competitiveness" [13,3] impelled by competitive entrance exams can effectively produce highly academic and disciplined future workers for capital industries. According to Lee, Korean families continue to experience educational fever in the 21th century, which highlights the pursuit of high academic success among students and families [14]. As a result, Koreans' expenditure on private tutorials considerably accounted for more than 2\% of GDP in 2008. Korea National Statistical Office reported that more than $70 \%$ of K-12 South Korean students participated in shadow education [15]. In 2017, around $82 \%$ of elementary school students and more than $55 \%$ of secondary school students engaged in private tutoring [16]. Lee proposed that the large-scale surge of the shadow education market weakened the dominate role of schooling and put households into a financial dilemma confronting 
economic burdens [17]. Therefore, the Korean government launched a series of policies to rectify the shadow education industry and demands.

\subsubsection{Implementation}

Revolutions in the past decades have been taken place by successive Korean administrations [6][13]. In 1974, Korean authorities launched a policy to allocate school places to students in high school enrollment. The lottery system totally replaced the entrance exams in secondary school. In 1980, President Chun took the most radical action to restrict $\mathrm{SE}$. He solidified the state's control over the college entrance examinations by reducing individual institutions' previous dominance and prohibiting private tutoring corresponding school subjects. However, the prohibition was hard to be implemented since households tried ticks to dodge these regulations and escape censure from authorities; the pressure and anxiety to prepare for college continued to move to even lower academic levels [13]. Moreover, families of higher socioeconomic statuses were found to easily afford such consumption to assist their children's early study [6]. Later, acknowledging the necessity of compromise, the government released its ban on SE by several issued policies, for example, allowing high school students to have private tutoring on holidays, permitting mainstream teachers to provide additional fee-paying lessons to their pupils [6]. Then a new initiative was launched in 2004 named as Policy for Reduction of Private Tutoring Expenditure through the Restoration of the Public Education System to improve the public's educational welfare. It acknowledged the bid to ban tutoring is superficial and shallow [6]. Ten new actions were taken in this policy. Some actions are as follows:
A. Offer e-leaning courses
B. Offer different levels of supplementary lessons after school based on school performance
C. Enrich extracurricular activities
D. Offer after classes for young elementary school students for working parents unable to send them to child-care center
E. Adoption of a diversified teacher evaluation system
F. Changing teaching and assessing methods
G. Prioritize high school records and extracurricular activities while reducing its focus on CSAT scores in the college entrance system

\subsubsection{Evaluation}

However, it is found that the policy was not effective for the implementation since the portion receiving SE in Korea kept growing from 1980 to 2007, shown in Figure 2. Lee pointed out that despite the Korean administration's policy attempting to alternative and reduce private tutoring by public services, many parents didn't consider the government' tutoring service as an effective substitute [17]. The institution producing varying college admission policies did little to shadow education spending, but the inherent educational fever in Korea should be acutely considered in reducing the SE scale (Bray, 2009).

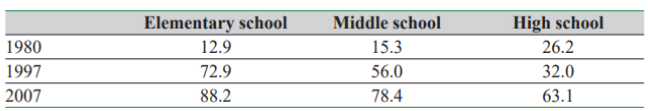

Figure 2 Percentage of pupils receiving private tutoring, Korea, 1980-2007 (Bray, 2009)

\subsubsection{America}

\subsubsection{Policy decision}

Shadow education in America received relatively a low level of attention in its domestic environment [17][18]. Given the high stakes of the SAT for secondary school students who are determined to attend tertiary institutions, the supplemental SAT preparation tutoring aimed at personal success in college entrance exam SAT has become a significant part of the American SE industry to offer private help [18]. It was reported that SAT preparation tutoring has grown into a profitable multi-million dollar scale: take the Princeton Review as an example which earned 110.4 million dollars for its provision of SAT preparation tutoring in 2009 as one of the reputable SE providers. It was found that American households with higher income (for example, more than 50000 dollars) are more likely to devote financial supports into private courses and private tutoring for test preparation than lower-income families, who are more likely to have no preparation or incline to spend monetary costs mainly on buying books, videos or software. This research finding is shown in Figure 3 below.

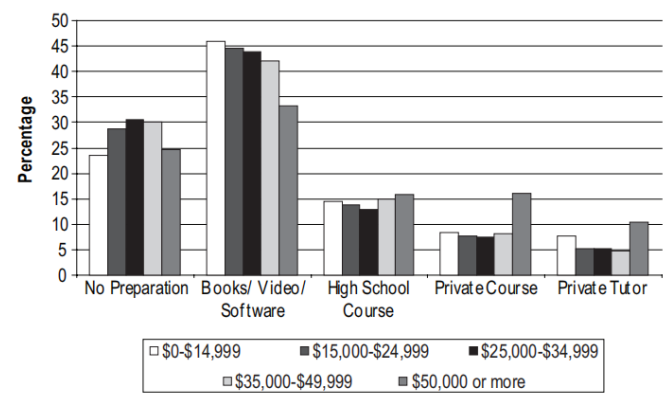

Figure 3 Highest-Level Test Preparation by Family Income

The U.S. Department of Education launched No Child Left Behind (NCLB) in 2001 to increase flexibility and stronger accountability of States and schools and to accelerate educational standardization. The new law requires low-income students with poor school study achievements failing to meet national standards for three years to obtain supplemental tutoring. 
The provision of supplemental services contributes to students' access to a quality education by diminishing failing schools' adverse effects (ibid.). As the U.S. DOE explained, parents should be aware that their children can have extra tutoring help or after-school supplement educational services in poor-performing schools that need improvements. It can be seen that these acts are initially aimed at increasing multiple choices and remedial resources for parents or students in poor schooling backgrounds.

\subsubsection{Policy implementation}

Concrete actions were conducted for NCLB: "school districts with one or more schools in the second year of school improvement must provide parents with a list of the supplemental free learning programs available in their area so that parents have a full set of options regarding services their children may need to succeed in learning at their grade level". The NCLB program allows educational services privately offered and publicly subsidized to be individually chosen by low-achieving and disadvantaged students [17]. Some services are also provided by non-profit communities or in-service school teachers [17]. The supplemental services are only available to students who have free lunch in school, which generally cater to low-income students.

The launched policy made substantial actions on the American schooling institution. For the supplementary tutoring program in June, 200, approximately 20 percent of low-income students (around 250000) took part in it . Take New York as an example. Nearly one-fifth of New York schools were on the school list for poor performance, while one-fifth of students were matched for extra supplemental tutoring. As for the supplemental service providers, it was reported that more than half of them were private (around 69\%), one-forth represented schools, the minor rests were university programs or unknown institutions in 2004 [19]. Koyama, in his research, noted the disparities of accountability allocated to school principals and supplemental education providers: school principals needed to undertake the majority accountability for students' progress while supplemental service providers had little responsibility for this. In her research, the following findings were uncovered. Due to the limited state funds for administrative fees related to supplemental educational programs, which the schools may compensate, many principals mediated their patterns of implementing the policy by reducing the number of enrolled students by personal manipulation to cut down expenses. Besides, some principals selected students in their favor. For example, a principal only chose eligible students in the medium-study level to attend supplemental tutoring. In contrast, children of the higher or lower level were mostly excluded from the program. Principles also tried to exert impacts on supplemental service directors and service providers and persuaded them to demonstrate progressive results by presenting test scores. Providers who didn't prove their efficiency of tutoring programs to the principle by scores would be threatened to cancel the cooperation contract for the next year. As a result, the supplemental education providers arbitrarily fabricated scores to present students' improvement in their program with the purpose of maintaining their market share and commercial connections.

\subsubsection{Evaluation}

Taylor mentioned the NCLB policy's progress for its supplementary tutoring program in Chicago. A year after 2005, when the policy was implemented, assessments showed that students who participated in the after-school program improved their reading for 1.09 years and math for 0.94 years. The results were higher than those eligible but didn't receive the service, with an average improvement of 1.03 years and 0.92 years, respectively. However, this reform has drawbacks, such as the limited censor for students using free school meals, no general evaluation, and little provider accountability [6]. Moreover, that monitoring procedure may have ignored students who had real academic needs, and the quality of private tutoring services might haven't been convincingly guaranteed.

The provision of supplementary tutoring for low-income poor-performing students as a significant sector of NCLB Policy is a governmental-driven and funded program, distinguished from the market-driven, good-performing-student-target after-school tutoring [6]. Koyoma stated that NCLB switched the relations among governance, public schools, and the commercial market. Sunderman proposed that the supplemental education services of NVLB legitimized the intervention of the private session and allowed it into the field of public education [19]. Bray once proposed that the intercession of private business admitted by the official administration into the education field may lead to parents' further acknowledgement of its recognizable status in children's education even if the private education service is no longer funded by the government [6]. Meanwhile, school principals and officials of the education department who emerged to be powerful actors can exert strong impacts on managers and providers of supplemental tutoring. As a result, the policy implementation was promoted, translated, and transformed with idea collisions among different stakeholders.

\subsubsection{Double Alleviation Policy in China}

Double Alleviation Policy is a new policy launched by the Chinese State Council on July 24th, 2021. Due to its short time span of implementation when the essay 
was written, the third stage is eliminated and should be conducted in future analysis.

\subsubsection{Policy decision}

Annual Report on New Types of Education Suppliers 2017 showed that the scale of shadow education in China grew to 490 billion yuan (around 76 billion dollars) in 2017 with average tuition fees of around 5.616 thousand yuan ( 867 dollars) per student, while the overall population receiving shadow education at the K12 stage in 2017 took the percentage of $48.4 \%$ [20], implying near half of the Chinese students were involved in private tutoring for study improvement.

In recent years, the birth rate of newborns in China has shown an obvious downward trend. Even lower than Japan. At one point, it was tied with South Korea. In many families, as parents, in addition to being busy with work, more energy, expenditure and time are spent on family education, leading to the difficulty to bear a second child. Parents have been overwhelmed by the children's education expenditures, in which the after-school private tutoring program also accounts for a large proportion. Liang pointed out that currently, education and medical care expenses have become a significant concern that plagues most families [21]. Some highly profitable educational institutions often overburden some families. As the official profile declared, it seriously offsets the fruits of the Chinese educational reform and development.

In view of the above, the General Office of the Central Committee of the Communist Party of China and the General Office of the State Council issued the "Opinions on Further Reducing the Burden of Students' Homework and Off-campus Training in Compulsory Education." in July of 2021, in which the following measures for supervising after-school tutoring are announced:

- All regions no longer approve new subject-based off-campus training institutions for students in the compulsory education stage. Existing subject-based training institutions are uniformly registered as non-profit institutions. Online academic institutions are changed to an approval system. Academic training institutions are not allowed to be listed for financing. Capitalization operation is strictly prohibited, and non-discipline training institutions shall be classified and approved strictly.

- Private training service behaviors should be standardized by establishing training content filing and supervision systems.

- To organise academic training, off-campus training institutions must not occupy national statutory holidays, weekends, and winter and summer vacations.
- Training institution financing and fees should be mainly used for the training business. Unfair competition should be resolutely prohibited, as well as hiring foreign personnel abroad to carry out tutoring.

\subsubsection{Implementation}

After the Ministry of Education introduced the double reduction policy, various provinces were reinforced to respond to the imperative. For example, on August 18, 2021, the General Office of the Beijing Municipal Committee of the Communist Party of China and the General Office of the Beijing Municipal People's Government issued a notice on "Beijing Measures to Further Reduce the Work Burden of Students in Compulsory Education and the Burden of Off-campus Training". On August 25, 2021, in order to fully implement the Shuangjian work deployment, the Shanghai Municipal Education Commission issued several measures to strengthen homework supervision, upgrade after-school services, and promote the mobility of distinct teachers to strengthen school education's status. By the principle of respecting the needs of students and working parents, the after-school services of compulsory education schools are required to implement the " $5+2$ " model, which is, 5 working days a week with at least 2 hours per day, the end time is aligned with the local normal off-duty time. On September 1, the director of the Office of the Education Supervision Committee of the State Council introduced the progress of implementing the Shuangjian Policy. He stipulated it is necessary to build a high-quality supervisory team with currently a cohort of 147,000 faculty across school levels, whose accountability of educational supervision are considered by the government as critical support for successful policy supervision.

\subsection{Thoughts on the policy}

In South Korea and China where SE is more prevalent, policies counteracting the shadow education industry focus on government intervention. The two countries both have imposed strict restrictions on private tutoring; however, the United States, through the government's cooperation with private educational enterprises, provided encouraging policies by supporting disadvantaged students with public funds to participate in SE after school. The national administrator has taken those actions in the three countries due to different settings. Nevertheless, the SE development in the U.S. is still modest for its scale. The government hopes to encourage the private sector into public education to fill in the gap that those disadvantaged schooling systems can't settle and resolve disadvantaged students' individual needs, which have been poorly catered for by the school education. Conversely, the SE scale in China 
and South Korea is huge enough to affect public education, educational equity, household financial burdens and social class mobility.

However, in South Korea, various regulations for shadow education have not eradicated supplementary tutoring programs for the last few decades. Critics considered that tutoring couldn't be completely tackled unless it became needless through cutting tutoring' competency and through improving mainstream education's quality [6]. As a publication, some experts commented, Korean authorities' bans on SE is like " trying to eliminate robbery by ensuring that the entire population is poor" ; however, under the competitive Asian context, to meet the lowest social class by legislation seems to be meaningless. Since the 1990s, the government recognized the failure of its prohibition policy and tried to adopt a more moderate measure. On the one hand, it re-recognized shadow education's legality in the market; on the other hand, it involved more school services on the campus, such as e-learning courses and supplementary lessons for different levels of students to enrich school education. These actions were considered as a way to enhance the main role of the school, which is also the case in China's current Double Alleviation policy. Currently, the Chinese government has adopted a similar method used in the history of the Korean government by restricting the development of the supplementary tutoring industry and offering after-school services. Since July 2021, private supplementary tutoring has been strictly prohibited from entering the public education field, and from September of 2021, schools of the Nine-Year compulsory education are subject to the " $5+2$ " pattern to offer after-class services, which means assuring at least 2 hours of after-class services for five working days (from Monday to Friday). It is speculated that the original intention of American administrators to formulate this policy by allowing private sectors to offer supplementary tutoring is to allow every child to receive sufficient educational resources, rather than simply being restricted by their poor family financial background and poor local school resources. The US government's approach fully respects the principles of market economy and protects independent choices from poor families in the education market. They can have the right to receive government funds to receive their favourite types of shadow education. The US approach is economically similar to France and Britain, offering governmental financial support for family SE participation. The French government designed preferential taxation to prompt families to investigate extracurricular tutoring programs [6]. Britain initiated a program in 2003 to afford total expenditures for students who took part in one-one private tutoring programs to reduce educational achievements [6]. However, these practices recognize to a certain extent the legitimacy of private remedial education in the field of public education. If the government no longer provides financial support in the possible future, parents should also pay for their children to have such forms of private remedial tutoring. The issues of educational inequality and social disparities caused by supplementary education may intensify. In addition, considering the considerable number of American students from low-income families and tuition fees' price in the American market, the policy implementation requires steadily and sufficiently guaranteed financial support. If the funds cannot be secured, governmental assistance will become empty talk.

Can the Double Alleviation Policy ban the private tutoring industry indeed? In despite that the tutoring culture is deeply embedded in Chinese educational tradition, the fact of the Chinese government's close and effective united cooperation among various central departments in policy formulation, strong competence in policy implementation, and the high subordination of local education departments and government agencies to the central government should never be neglected. On June 15th, the Ministry of Education of China established a new department to regulate extracurricular tutoring institutions and emphasized rectifying and supervising the education market. In August of 2021, the State Council required local governments to report on their implemental progress of the Double Alleviation Policy for half a month to facilitate the central government's supervision and review of the local conducting progress. As Wliimams and Cummings pointed out, leadership, source support, theoretical compatibility and implemental persistence are contributive to the success of reform [12]. The shadow education industry in China can shrink to a low scale and intensity will decline apparently, should this policy implementation be insisted with warranted strong leadership and a long-term aim,

Another question is whether people's demand for shadow education will decrease. Though it is through China's strong capacity of policy implementation that extracurricular institutions can be enforced to change their previous institutional habits and reduce their scale, what deserves the discussion is the capability of after-class services to meet households' actual needs, as they acquired from the private institutions in the past. Shadow education may be diminished by a small-scale industry that is not large enough to affect society only when parents and students really reduce their needs. On social media, the double reduction policy has received general support from parents due to its alleviation of conflicts between work and beholding their children at home, allowing them to get a caring commitment from school when parents are still involved in work in the after-class time. However, there are concerns in the possible increasing pressure on teachers of the nine-year compulsory education stage. In August, the Jiangsu Department of Education stipulates that teachers can 
have a salary of 60 yuan (around 9.3 dollars) per lesson for after-school services. As a result, there are increasing complaints from teachers on social media. Furthermore, there are cases that some teachers who are unwilling to participate in after-school services discourage parents from sending their children to sign up for those service. Further studies on teachers' policy reflection need to conducted and relative issues deserve the administrator' attention.

Lee, in his study, proposed private tutoring is induced by needs for "academic remediation and compensation for limited schooling"[17], which is more general in countries with lower academic attainment and worse schooling facilities. Compared with South Korea, the United states has a larger portion of public teacher resources and a higher likelihood of entering tertiary education [17]. Comparatively, in the context of China, the schooling quality differs significantly between urban and rural areas of unevenly distributed sources. Simply strengthening or extending current schooling settings and teaching methods may not be enough to reduce the need for private tutoring among kids and their parents. At the same time, teachers' perceptions of school quality, on the other hand, are unlikely to reflect parents' or students' satisfaction with education [17]. The after-school service can't simply be a homogeneous extension of schooling time that does not result in individualized instruction, which is the remarkable essence of shadow education. In doing so, the extended version of schooling time may intensify school inter-competition instead of improving mainstream education on a qualitative level. The school should be able to provide students with a menu-style personalized selection of after-class services as the private tutoring institutions do. The Korean experience of providing segmented additional tutoring sectors for students of different learning achievements can be drawn upon in Chines after-class services. Furthermore, the United States' standardized evaluation of school teaching quality and educational performance can be applied to China's Double Alleviation Policy. For students who study in a poor schooling background, after-school service time should be effectively utilized to compensate for schools' deficiency. By involving more off-campus forces, such as hiring retiring teachers, professionals or social workers, as well as merit teachers from other schools offering remote courses can participate in this program to providing personalized or group tutoring services for students with unsatisfactory performance; in addition, some social resources such as youth activity centers and social volunteers can provide students with various types of quality education such as art. It is attentive that the current local implementation of the double reduction policy seems to be still indistinct in offering concrete schemes for concretely structuring the program and involving a diversified workforce and extra innovative resources in the service while the time and funding arrangements have been introduced. These things are specific and serious issues that should be considered in the long-term process of policy implementation.

\section{CONCLUSION}

This essay has examined the shadow education policies among South Korea, the United States, and China. It is found that the education policies towards shadow education in different countries are significantly affected by schooling issues, private education's socioeconomic impacts, the status of market economy, and conventional governmental accustoms in different settings. It is found that Chinese and Korean policymakers both set stringent limitations on private tutoring in the market, while the United States administrator has joined supplemental tutoring's efforts into the field of public education by cooperation with private sectors. More research should be done to understand how the local education council implements the current Double Alleviation Policy. Besides, teachers as the main executor of school education, their attitudes and implementation methods of Double Alleviation Policy should also be investigated to understand potential effects on the long-term policy exertion.

\section{REFERENCES}

[1]Ministry of Education of the People's Republic of China, Opinions on Further Reducing the Burden of Students' Homework and Off-campus Training inCompulsory Education, 2021. Site: http://www.moe.gov.cn/jyb_xwfb/gzdt_gzdt/s5987/ 202107/t20210724_546566.html

[2]H. A. Dang, H. Rogers. How to interpret the growing phenomenon of private tutoring: human capital deepening inequality increasing, or waste of resources? Policy Research Working Paper 4530. Washington, DC: The World Bank, 20085. DOI: https://ssrn.com/abstract=1098628.

[3]M. Bray, Private supplementary tutoring: comparative perspectives on patterns and implications, Compare: A Journal of Comparative Education, vol.4, 2006, pp. 515-530. DOI: $10.1080 / 03057920601024974$

[4]S. Gao, Involution: The cultural reproduction of school education. Education Research and Experiment, vol.4, 2020,pp 13-18. DOI:CNKI:SUN:YJSY.0.2020-04-002.

[5]M. Bray, Researching shadow education: Methodological challenges and directions. Asia Pacific Education Review, vol. 11, 2010, pp. 3-13. DOI: $10.1007 / \mathrm{s} 12564-009-9056-6$ 
[6]M. Bray, Confronting the shadow education system: What government policies for what private tutoring?. United Nations Educational, Scientific and Cultural Organization; International Institute for Educational Planning, 2009.

[7]D. L. Stevenson, D. P. Baker, Shadow education and allocation in formal schooling: Transition to university in Japan. American Journal of Sociology, vol. 6, 1992, pp. 1639-1657.

[8]J. Ireson, Private tutoring: how prevalent and effective is it?. London Review ofEducation, vol. 2, pp. $109-122, \quad 2004 . \quad$ DOI: $10.1080 / 1474846042000229458$.

[9]E. W. Gordon, B. L. Bridglall, and A. S.Meroe, eds. Supplementary education: the hidden curriculum of high academic achievement, Lanham, MD: Rowman \& Littlefield, 2005.

[10]Kumon, Kumon Institute of Education.Retrieved 28 July 2008 from www.kumon.ne.jp/english/index.html 2008.

[11]D.P. Warwick, F. Reimers, N. McGinn, The implementation of educationalinnovations: Lessons from Pakistan. International Journal of Educational 'Development, vol.4, 1992, pp. 297 - 307. DOI:https://doi.org/10.1016/0738-0593(92)900057.

[12]J. H. Williams, W. K. Cummings,Policy-making for education reform in developing countries: Contexts and processes. Lanham, MD: Scarecrow Press, 2005.

[13]M.J. Seth, Education fever: society, politics, and the pursuit of schooling in South Korea. Honolulu: University of Hawaii Press, 2002.

[14]S. Lee, Relationship among education fever, the college-admission policy, and shadoweducation in South Korea. KEDI Journal of Educational Policy, vol.15, 2018.

[15]Korea National Statistical Office, The survey of private education expenditures in 2010. Seoul: Korea National StatisticalOffice, 2011. Retrieved from: http://www.nso.go.kr/, 2021.

[16]Statistics Korea, 2017 survey on private tutoring expenditures, Seoul, Republic of Korea: Author, 2018.

[17]J. Lee, Two worlds of private tutoring: The prevalence and causes of after-schoolmathematics tutoring in Korea and the United States. Teachers College Record, vol. 109, 2007, pp. 1207-1234.

[18]C. Buchmann, D. J. Condron, V. J. Roscigno. Shadow education, American style: Test preparation, the SAT andcollegeenrollment, Social forces, vol. 89, 2010, pp. 435-461. DOI: $10.1353 /$ sof.2010.0053

[19]G. L. Sunderman, Policy Brief, Supplemental Educational Services under NCLB: Charting Implementation. Los Angeles: Civil Rights Project, UCLA, 2007. DOI:

https://escholarship.org/uc/item/68z4d9j4

[20]New Types of Education Suppliers, Social Sciences Academic Press(CHINA), Beijing, 2017.

Retrieved from: http://tt.cssn.cn/zk/zk_zkbg/201807/t20180711_45 01315_1.shtml, 2021.

[21]J. Liang, After-school service "5+2" promotes the implementation of Double Reduction. Huaxing Times, vol.6, 2021. 